\title{
Spektroskopi Reflektansi Sampel Tanah dan Batuan yang Mengandung Mineral Pembawa Unsur Tanah Jarang dan Radioaktif
}

\section{Reflectance Spectroscopy of Soils and Rocks Containing Rare Earth Element- and Radioactive-bearing Minerals}

\author{
Arie Naftali Hawu Hede ${ }^{1, *}$, Muhammad Anugrah Firdaus ${ }^{2}$, Yogi La Ode Prianata ${ }^{2}$, \\ Mohamad Nur Heriawan ${ }^{1}$, Syafrizal ${ }^{1}$, Heri Syaeful ${ }^{3}$, Ichwan Azwardi Lubis ${ }^{4}$ \\ ${ }^{1}$ Kelompok Keahlian Eksplorasi Sumberdaya Bumi, Fakultas Teknik Pertambangan dan Perminyakan, Institut \\ Teknologi Bandung, Jl. Ganesha No. 10, Bandung, Indonesia, 40132 \\ ${ }^{2}$ Program Magister Rekayasa Pertambangan, Fakultas Teknik Pertambangan dan Perminyakan, Institut Teknologi \\ Bandung, Jl. Ganesha No. 10, Bandung, Indonesia, 40132 \\ ${ }^{3}$ Pusat Teknologi Bahan Galian Nuklir-BATAN, Jl. Lebak Bulus Raya No. 9, Ps. Jumat, Jakarta, 12440 \\ ${ }^{4}$ PT Timah (Persero) Tbk, Jl. Jenderal Sudirman No. 51, Pangkal Pinang, Bangka, Indonesia, 33121 \\ "E-mail: naftali@mining.itb.ac.id
}

Naskah diterima: 1 November 2019, direvisi: 18 November 2019, disetujui: 22 November 2019

DOI: 10.17146/eksplorium.2019.40.2.5644

\begin{abstract}
ABSTRAK
Spektroskopi reflektansi merupakan salah satu metode nondestruktif untuk identifikasi mineral dan sebagai dasar dalam analisis pengindraan jauh (indraja) sensor optik. Penelitian ini bertujuan melakukan kajian penerapan spektroskopi reflektansi pada panjang gelombang 350-2.500 nm untuk sampel tanah dan batuan pembawa unsur tanah jarang (rare earth element-REE) dan radioaktif. Sampel diambil dari beberapa lokasi di Bangka Selatan dan Mamuju yang sebelumnya telah diidentifikasi memiliki potensi REE dan unsur radioaktif. Kurva reflektansi hasil analisis sampel dari Bangka Selatan menunjukan adanya kenampakan absorpsi yang menjadi karakteristik untuk kehadiran REE, dalam bentuk mineral monasit, zirkon, dan xenotime khususnya pada sampel yang berasal dari material tailing dan konsentrat bijih timah. Panjang gelombang yang menjadi kunci khususnya berada pada rentang visible-near infrared (VNIR; 400-1.300 nm). Sedangkan untuk sampel yang berasal dari Mamuju, yang merupakan daerah prospeksi mineral radioaktif, karakteristik spektral memperlihatkan beberapa panjang gelombang kunci terutama pada rentang shortwave infrared $(1.300-2.500 \mathrm{~nm})$. Hasil interpretasi menunjukkan mineral mayor berupa mineral lempung, sulfat, spesies $\mathrm{NH}_{4}$, dan mineral yang mengandung $\mathrm{Al}-\mathrm{OH}$ lainnya, sedangkan untuk beberapa sampel pada panjang gelombang VNIR diidentifikasi mengandung mineral besi oksida/hidroksida. Hasil penelitian ini diharapkan dapat berguna untuk pemetaan eksplorasi REE dan radioaktif dengan menggunakan metode indraja.
\end{abstract}

Kata kunci: spektroskopi reflektansi, mineral, unsur tanah jarang, radioaktif

\begin{abstract}
Reflectance spectroscopy is one of the nondestructive methods of mineral identification and is one of the basic principles in the remote sensing analysis using optical sensors. This research aimed at applying reflectance spectroscopy at 350-2,500 $\mathrm{nm}$ wavelength range for samples containing rare earth elements (REE) and radioactive minerals. Samples were taken from several locations in South Bangka and Mamuju that had previously been identified as potential location of REE and radioactive-bearing minerals. Reflectance data shows that there are absorption characteristics for REE-bearing minerals; monazite, zircon, and xenotime minerals especially from tailings and tin ore concentrate for the samples from South Bangka. The key wavelengths are specifically in the visible-near infrared range (VNIR; 400-1300 nm). For the samples from Mamuju, which is known as radioactive mineral prospecting areas, spectral characteristics provide information that there are spectral signatures in the shortwave infrared range $(1,300-2,500 \mathrm{~nm})$. The results of major mineral
\end{abstract}


interpretations include clay minerals, sulfates, $\mathrm{NH}_{4}$ species, and other minerals containing Al-OH. However, some samples at the VNIR wavelength identified as iron oxide/hydroxide minerals. It is hoped that these results can be useful for REE and radioactive exploration mapping using remote sensing methods.

Keywords: reflectance spectroscopy, minerals, rare earth elements, radioactive

\section{PENDAHULUAN}

Pemanfaatan spektroskopi reflektansi dan pencitraan hiperspektral dalam pengindraan jauh (indraja) terbukti ampuh untuk mengetahui informasi mineralogi pada daerah terpencil atau tidak terjangkau, yaitu ketika informasi tersebut sulit ditentukan oleh teknik eksplorasi lainnya [1-3]. Identifikasi mineral dapat dilakukan dengan spektroskopi gelombang elektromagnetik panjang gelombang tampak hingga inframerah dekat (visible-near infrared/VNIR) 350-1.300 nm, inframerah gelombang pendek (shortwave infrared/SWIR) $\quad 1.300-2.500 \mathrm{~nm}$, dan inframerah gelombang panjang (long-wave infrared/LWIR) 8.000-14.000 nm [4-6].

Penelitian ini memanfaatkan respon spektral pada rentang VNIR dan SWIR untuk mengindentifikasi jenis mineral. Prinsip dasar spektroskopi reflektansi menggunakan kenampakan spektral untuk interpretasi material. Atom dan molekul tertentu menyerap (absorb) energi sebagai fungsi dari struktur atomik [7, 8]. Penyerapan atau absorpsi ini terjadi pada posisi panjang gelombang tertentu dengan tingkat energi yang menentukan panjang gelombang adalah fungsi dari ukuran jari-jari ion kation yang terikat pada molekul yang berbeda. Panjang ikatan antara atom dan molekul tertentu adalah tetap, sehingga prediksi komposisi dan perubahan komposisi dari mineral pada absorpsi yang terjadi dapat dilakukan. Penelitian spektral pada skala laboratorium menunjukan bahwa beberapa parameter respon spektral seperti bentuk absorpsi, posisi minimum, kedalaman absorpsi, lebar, luas daerah, reflektansi absolut, dan kombinasi dari berbagai parameter tersebut dapat digunakan untuk menganalisis informasi fisik material dan properti kimia, kelimpahan, kelembaban, ukuran butir, dan lain-lain, baik secara kualitatif maupun kuantitatif [9, 10]. Berbagai misi observasi bumi yang telah dikembangkan maupun direncanakan seperti EO-1 Hyperion (misi sudah berakhir), Precursore Iperspettrale della Missione Applicativa-PRISMA (2019, Italia), dan Environmental Mapping and Analysis Program-EnMAP (2020, Jerman), memungkinkan teknologi non-desktruktif ini akan tersedia secara global untuk dapat memantau dan memetakan permukaan bumi yang kompleks, termasuk untuk ekstraksi informasi komponen tanah dan batuan. Indonesia saat ini sedang mengembangkan material maju seperti unsur tanah jarang (rare earth elements-REE) dan unsur radioaktif untuk keperluan sumber energi [11]. Keberadaan endapan REE dan unsur radioaktif dapat berupa endapan primer sebagai hasil proses magmatik maupun hidrotermal dan banyak dijumpai sebagai endapan sekunder dalam bentuk rombakan sedimentasi (placer) dan produk pelapukan (lateritik). Penyebaran REE dan unsur radioaktif di Indonesia banyak ditemukan berasosiasi dengan batuan granit yang terdapat di sepanjang jalur timah (Sumatra bagian barat, Bangka-Belitung), Kalimantan bagian barat, Sulawesi bagian barat hingga Papua [12-14]. 
Guna mendukung eksplorasi REE dan mineral radioaktif di Indonesia, penelitian dan penyusunan database hiperspektral yang dapat dimanfaatkan pada kegiatan prospeksi/eksplorasi pendahuluan dengan indraja sangat diperlukan. Metode indraja untuk eksplorasi endapan REE dan radioaktif di Indonesia sebelumnya banyak memanfaatkan pengolahan citra untuk analisis struktur, interpretasi warna, citra komposit, dan analisis reflektansi multispektral [15-17]. Penelitian ini bertujuan untuk mempelajari karakteristik yang khas pada pencitraan hiperspektral untuk sampel mineral dan batuan pembawa REE dan unsur radioaktif di Indonesia khususnya yang berasal dari Bangka Selatan dan Mamuju (Gambar 1). Basis data (database) yang dihasilkan dapat mendukung keperluan penelitian lanjutan termasuk integrasinya dengan metode eksplorasi lainnya.

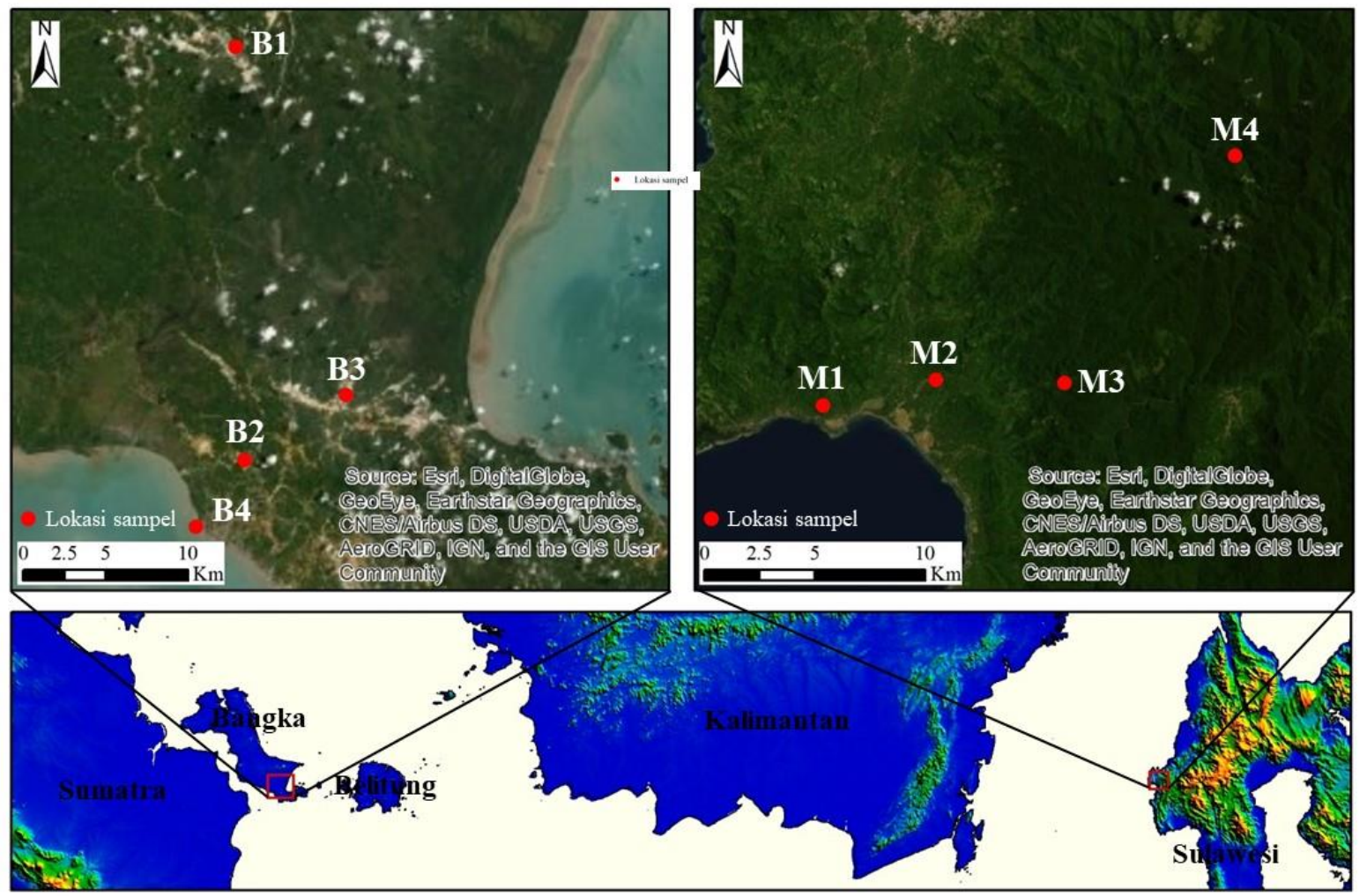

Gambar 1. Lokasi sampel dari Bangka Selatan dan Mamuju.

KONDISI UMUM LOKASI SAMPEL

Penelitian dilakukan pada dua lokasi yang berbeda, yaitu di Kabupaten Bangka Selatan, Provinsi Bangka Belitung untuk pengamatan terhadap REE dan di Kabupaten Mamuju, Provinsi Sulawesi Barat untuk pengamatan terhadap mineral radioaktif. Sampel berupa tanah dan batuan didapat dengan bantuan PT Timah (Persero) Tbk dan
Pusat Teknologi Bahan Galian Nuklir-Badan Tenaga Nuklir Nasional.

Lokasi penelitian REE di Pulau Bangka secara geologi merupakan kelanjutan dari tin mayor South East Asian tin belt yang membentang dari Burma, Thailand, Malaysia hingga Indonesia. Sabuk timah tersebut diperkirakan berumur Yura-Kapur dan didominasi oleh Granit Tipe S [18]. Di Pulau Bangka terdapat dua generasi granit, yaitu 
granit tua yang tidak mengandung kasiterit dan umumnya terdapat pada daerah rendah (Granit Klabat) dan granit muda sebagai pembawa timah yang umumnya telah tererosi lanjut [19].

Lokasi penelitian mineral radioaktif yang terletak di Kabupaten Mamuju tersebar di empat kecamatan yaitu Kecamatan Mamuju, Kecamatan Simboro, Kecamatan Tapalang, dan Kecamatan Tapalang Barat. Data Shuttle Radar Topography Mission (SRTM) menggambarkan bahwa daerah penelitian merupakan daerah dengan tipe morfologi perbukitan hingga pegunungan yang memiliki kelerengan yang sangat curam.

Daerah Mamuju secara umum tersusun atas kelompok batuan gunung api yang sangat bervariasi baik dari jenis maupun komposisinya. Berdasarkan data geologi regional, sebagian besar batuan gunung api yang terdapat di daerah penelitian adalah kelompok batuan gunung api Adang yang terbagi pada beberapa kompleks yaitu: kompleks Tapalang, kompleks Adang, kompleks Malunda, dan kompleks Ampalas berupa lava dan breksi vulkanik. Batuan sedimen muda didominasi oleh produk klastika gunung api dan batuan karbonat. Sedimen yang lebih muda adalah batuan konglomerat gunung api yang terbentuk dari hasil rombakan atau longsoran batuan gunung api yang bersifat grain supported [20].

\section{METODOLOGI}

Jenis sampel yang berasal dari Bangka Selatan berupa endapan timah aluvial (kode sampel B1), endapan timah primer (kode sampel B2), material tailing (kode sampel B3), dan konsentrat hasil pengolahan timah (kode sampel B4). Sampel yang berasal dari Mamuju berupa tanah dan batuan (kode sampel M1 s.d. M4). Sebaran lokasi sampel dapat dilihat pada Gambar 1. Preparasi sampel butir untuk pengukuran spektroskopi reflektasi dilakukan dengan menghaluskan sampel hingga berukuran $<0,25 \mathrm{~mm}$ agar menjadi homogen. Sementara itu, untuk sampel batuan dilakukan dengan cara menghaluskan sisi sampel (Gambar 2).

Pengukuran spektroskopi reflektansi dilakukan dengan menggunakan alat Analytical Spectral Device FieldSpec4. Secara teknis, spesifikasi alat ini memiliki rentang spektral 350-2.500 $\mathrm{nm}$ dengan resolusi $3 \mathrm{~nm}$ pada $700 \mathrm{~nm}$ dan $8 \mathrm{~nm}$ pada $1.400 / 2.100 \mathrm{~nm}$. Alat ini juga memiliki sampling interval $1,4 \mathrm{~nm}$ pada $350-1.000 \mathrm{~nm}$ dan $1,1 \mathrm{~nm}$ pada $1.001-2.500 \mathrm{~nm}$ serta waktu scanning yang mencapai $100 \mathrm{~ms}$.
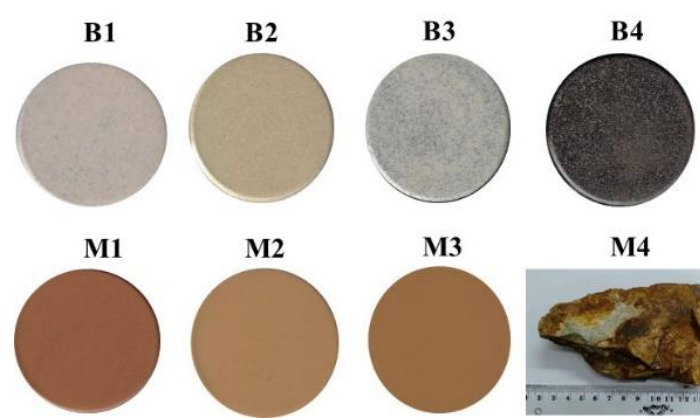

M4

Gambar 2. Sampel butir ukuran $<0,25 \mathrm{~mm}$ dalam cawan gelas ukuran diameter $6 \mathrm{~cm}$ dan sampel batuan untuk analisis spektroskopi reflektansi.

Pengukuran dilakukan dalam suasana laboratorium dan gelap dengan menggunakan alat aksesoris contact probe yang memiliki sumber energi cahaya internal lampu halogen 6,5 W dengan ukuran spot penyinaran $1 \mathrm{~cm}$. Proses smoothing kemudian dilakukan pada data hasil pengukuran, yang berupa kurva reflektansi dengan formula Savitzky-Golay filter untuk menghilangkan noise yang timbul selama proses pengukuran, khususnya pada rentang 350-400 nm. Persamaan yang digunakan dalam Savitzky-Golay filter tersebut pada dasarnya merupakan prinsip 
dari moving average. Ketika melakukan analisis kenampakan spektral reflektansi juga dilakukan normalisasi nilai menggunakan metode continuum removal agar dapat membandingkan kenampakan absorpsi mineral berdasarkan acuan (baseline) yang sama.

Basis data spektral milik United States Geological Survey (USGS) digunakan sebagai komparator dalam melakukan analisis spektral. Interpretasi mineral-mineral yang terdapat di daerah penelitian dilakukan dengan acuan hasil penelitian-penelitian sebelumnya $[13,14,21-24]$. Gambar 3 memperlihatkan tipikal reflektansi dalam rentang VNIR-SWIR untuk beberapa mineral beserta absorpsi khas yang terjadi sebagai acuan identifikasi jenis mineral. Selain itu untuk melengkapi interpretasi mineral digunakan data mikroskopi dan geokimia yang sudah diperoleh dari penelitian sebelumnya $[20,24]$

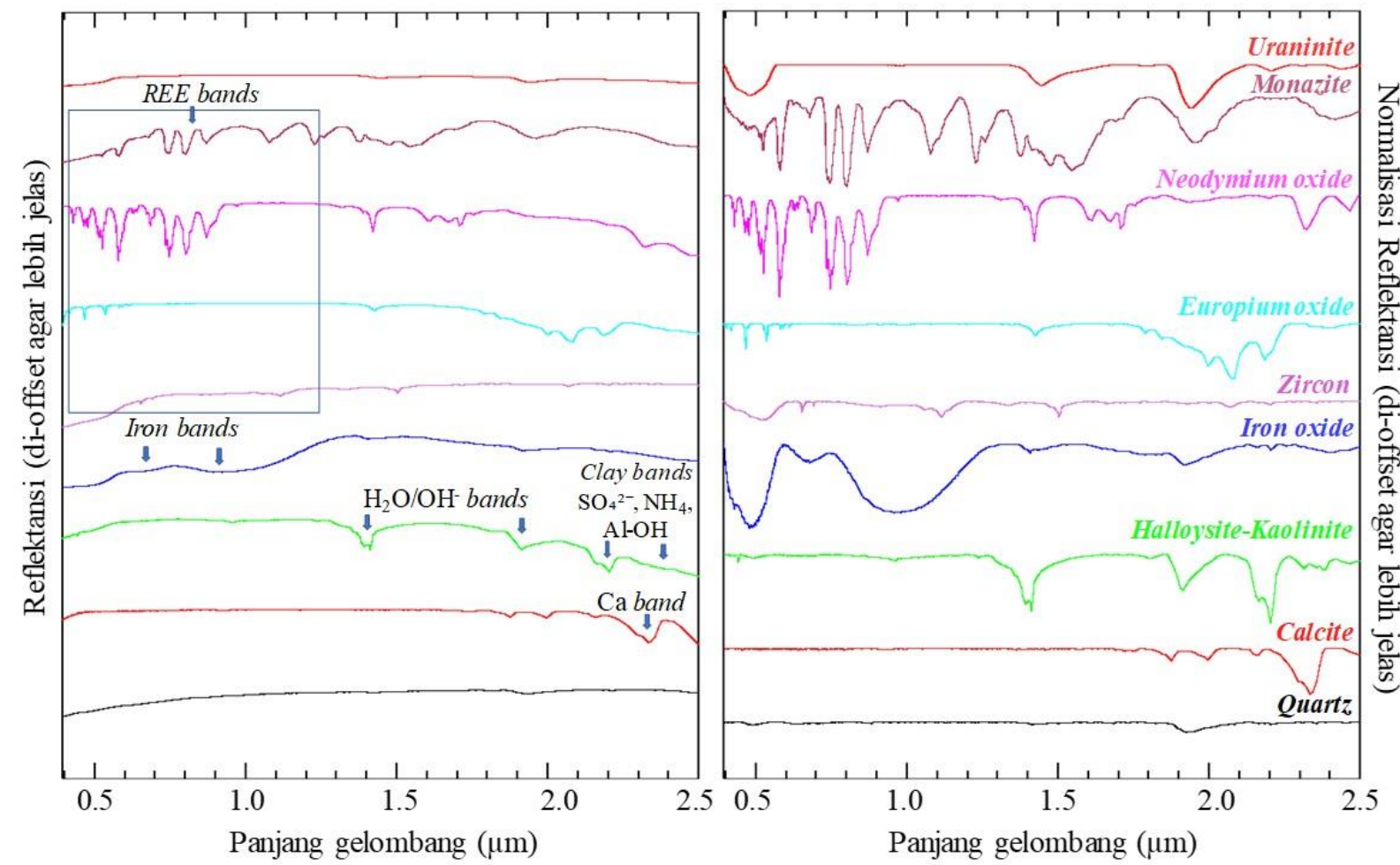

Gambar 3. Tipikal spektral VNIR-SWIR nilai reflektansi normal (gambar kiri) dan reflektansi yang dinormalisasi menggunakan continuum removal (gambar kanan) mineral umum, REE, dan radioaktif berdasar basis data spektral USGS beserta identifikasi band absorpsi.

\section{HASIL DAN PEMBAHASAN}

\section{Spektroskopi Reflektansi Sampel Bangka Selatan}

Sampel yang berasal dari Bangka Selatan diambil dari lokasi penambangan timah aktif. Berdasarkan jenis bijih, sampel tersebut terdiri dari sampel aluvial, primer, tailing, dan konsentrat. Analisis grain counting yang sudah dilakukan menunjukkan bahwa sampel konsentrat memiliki kandungan mineral REE (monasit, xenotime, dan zirkon) tertinggi [24]. Kondisi ini terjadi karena pada sampel konsentrat telah dilakukan proses konsentrasi sehingga mineral pengotor telah dieliminasi. Namun, pada sampel tailing juga masih dapat diidentifikasi kehadiran mineral REE yang cukup jelas terlihat.

Gambar 4 menunjukkan hasil pengukuran reflektansi untuk masing-masing sampel B1-B4 disertai dengan interpretasi 
band absorpsi yang terjadi. Kurva reflektansi ditunjukan dengan kurva normal dan kurva hasil normalisasi ditunjukan dengan menggunakan metode continuum removal agar dapat memperjelas lokasi absorpsi guna
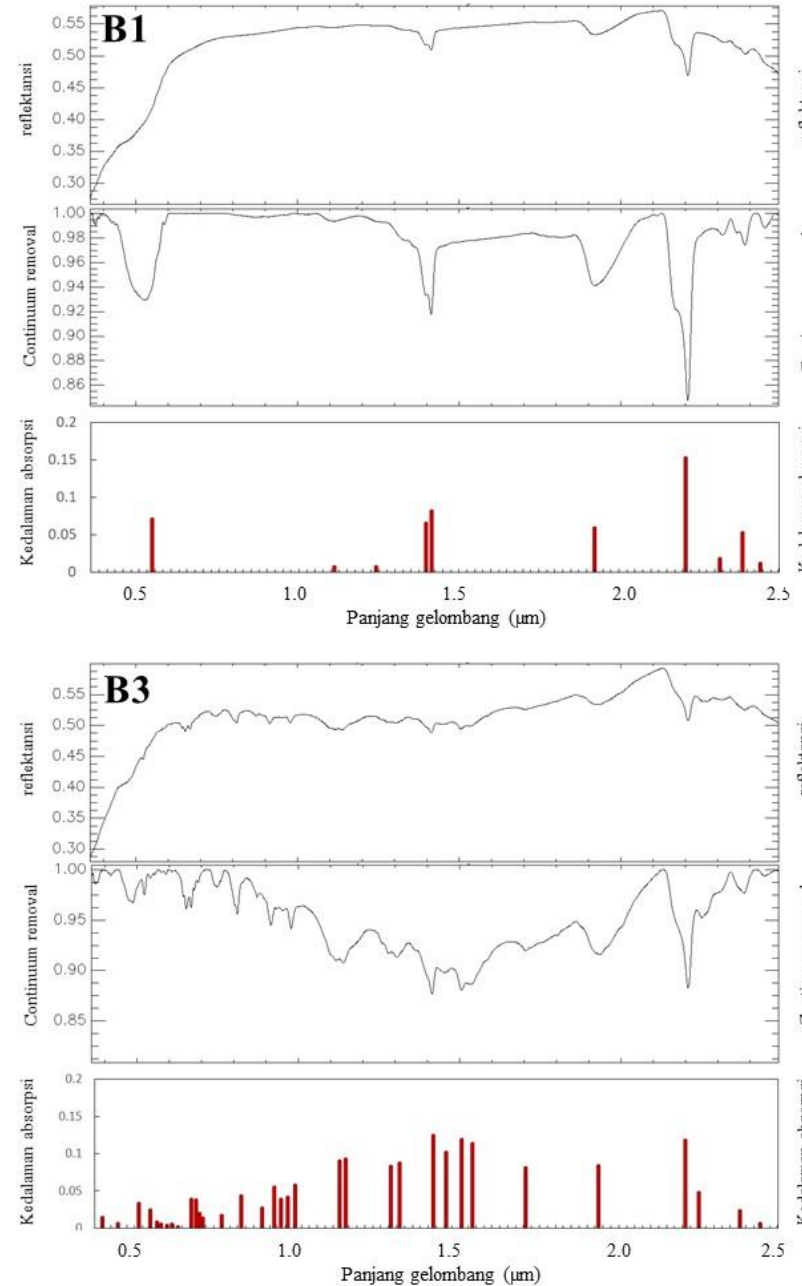

Gambar 4. Kurva reflektansi, normalisasi reflektansi dengan continuum removal, dan kedalaman absorpsi untuk masing-masing sampel B1 s.d. B4.

Spectral signature diagram didapatkan dengan menghitung full width at half maximum (FWHM) setiap puncak nilai absorpsi reflektansi. Nilai FWHM dapat dihitung dengan cara mengambil setengah dari nilai puncak absorpsi lalu diinterpolasikan terhadap kurva reflektansi sehingga didapatkan nilai rentang panjang gelombang tersebut. Metode FWHM identik dengan metode yang digunakan untuk
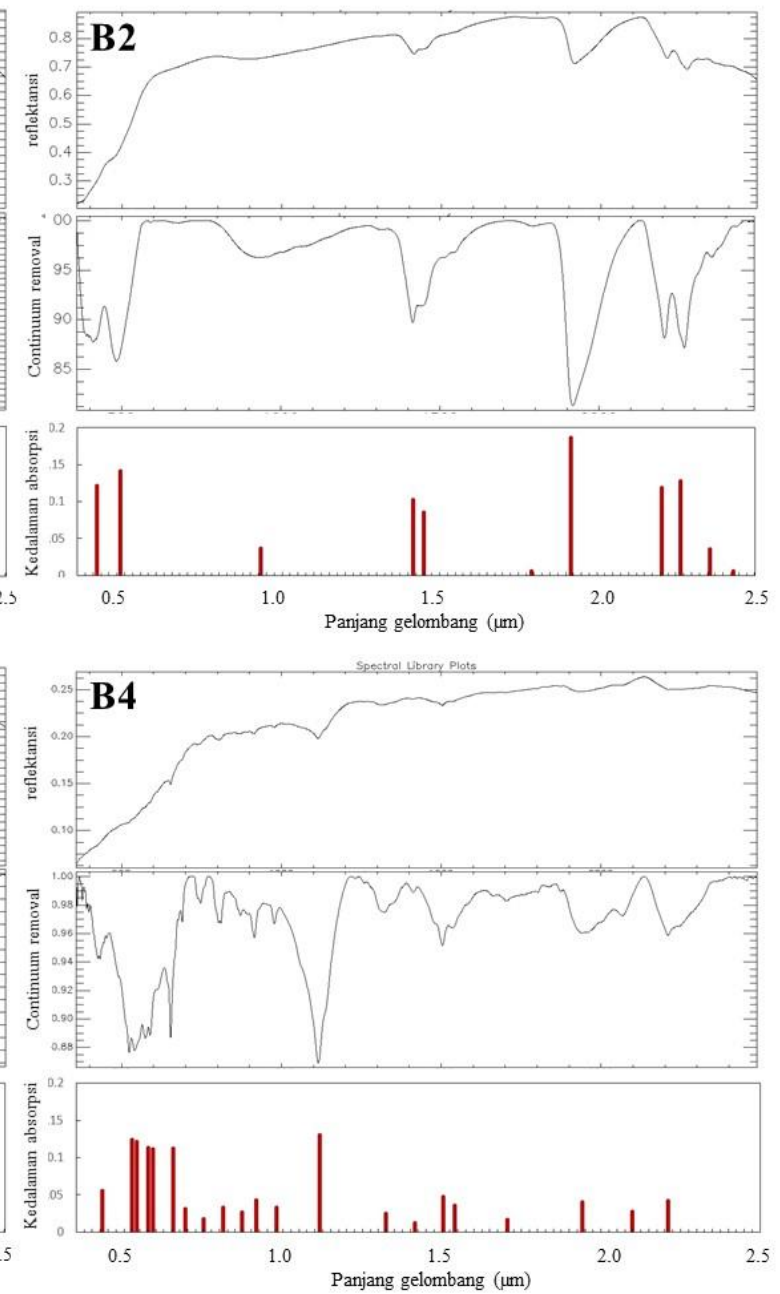

keperluan interpretasi. Lokasi band dan kedalaman absorpsi adalah salah satu kunci penting dalam interpretasi jenis mineral atau biasa disebut juga spectral signature diagram. 
memperlihatkan spektral dari setiap sampel, lokasi pengelompokan, dan absorpsi kuat yang disajikan dalam kurva. Sampel B3 dan B4 menunjukkan fitur absorpsi yang kuat untuk REE-fosfat termasuk fitur pembentukannya khususnya pada panjang gelombang VNIR dan beberapa pada SWIR.

Band absorpsi yang terjadi termasuk pola absorpsi yang lemah hingga kuat dan pada beberapa rentang panjang gelombang terdapat pola noise dan luasan. Panjang gelombang yang menjadi kunci khususnya berada pada rentang VNIR antara lain 480, 490, 524, 582, $654,670,740,800,814,915,980,1.000$, 1.120 , 1.140, dan $1.280 \mathrm{~nm}$. Secara umum terdapat beberapa kelompok absorpsi, antara lain: kelompok pertama pada panjang gelombang 400-600 nm; kelompok kedua pada panjang gelombang $600-700 \mathrm{~nm}$; kelompok ketiga memiliki ciri khas pada nilai minimum yang kuat di panjang gelombang $740 \mathrm{~nm}$; dan kelompok keempat pada rentang $800 \mathrm{~nm}$; diikuti oleh absorpsi tajam yang menjadi kelompok kelima. Selain itu, terdapat beberapa kelompok lain dengan absorpsi yang rendah. Kemudian, pada rentang SWIR juga terdapat beberapa kelompok absorpsi yang dapat menjadi indikasi kehadiran mineral REE, meskipun terkadang pada rentang ini kelompok tersebut dapat berinterferensi dengan mineral non-REE lainnya yang menjadi mineral utama di daerah Bangka Selatan seperti mineral lempung, kuarsa, dan mineral lainnya.

\section{Spektroskopi Reflektansi Sampel Mamuju}

Sampel M1 s.d. M3 diambil dari daerah Tapalang yang memiliki anomali radioaktif. Anomali radioaktif di daerah ini terdistribusi pada batuan basaltik yang termasuk dalam Formasi Adang. Keterdapatan mineral radioaktif di daerah ini dikontrol oleh struktur, jenis batuan dan tanah penyusunnya
$[15,22]$. Pengayaan mineral radioaktif terjadi karena beberapa aktivitas vulkanik di daerah Mamuju. Hal tersebut diperkuat dengan analisis indraja yang menunjukkan banyaknya fitur melingkar di daerah Mamuju dan ditafsirkan sebagai pusat kegiatan vulkanik, termasuk daerah Tapalang [16].

Sampel M4 terletak di Kecamatan Mamuju yang secara geologi disusun oleh sebaran gunung api dan sedimen laut. Batuan gunung api Adang tersusun atas lava ponolit, piroklastika, dan tufitis memiliki nilai radioaktivitas tinggi yang berasal dari mineral penyusunnya. Nilai radioaktif yang tinggi ditunjukan oleh sampel M4 yang diperkirakan berasal dari gunung api Adang dan memiliki kandungan radioaktif alami. Satuan batuan gunung api Adang dapat dikelompokkan menjadi tujuh, yaitu komplek Tapalang, Ampalas, Adang, Malunda, Karampuang, Sumare, dan Labuan Rano [23].

Dari sisi spektroskopi reflektansi, mineral radioaktif telah banyak diselidiki dalam kaitan interaksinya dengan gelombang elektromagnetik khususnya dalam rentang VNIR-SWIR [26]. Identifikasi karakteristik mineral menggunakan metode spektroskopi dengan menggunakan infrared transmission spectroscopy mampu membedakan berbagai konsentrat dan bijih uranium. Panjang gelombang NIR telah terbukti sebagai teknik non-destruktif yang mampu mengidentifikasi variasi dari endapan uranium.

Hasil interpretasi pada sampel M1 s.d. M4 memperlihatkan kehadiran mineral mayor antara lain mineral lempung, sulfat, spesies $\mathrm{NH}_{4}$, dan mineral yang mengandung $\mathrm{Al}-\mathrm{OH}$ lainnya (Gambar 5). Meski demikian untuk beberapa sampel pada panjang gelombang VNIR diidentifikasi mengandung mineral besi oksida/hidroksida contohnya sampel M1 dan M4. 

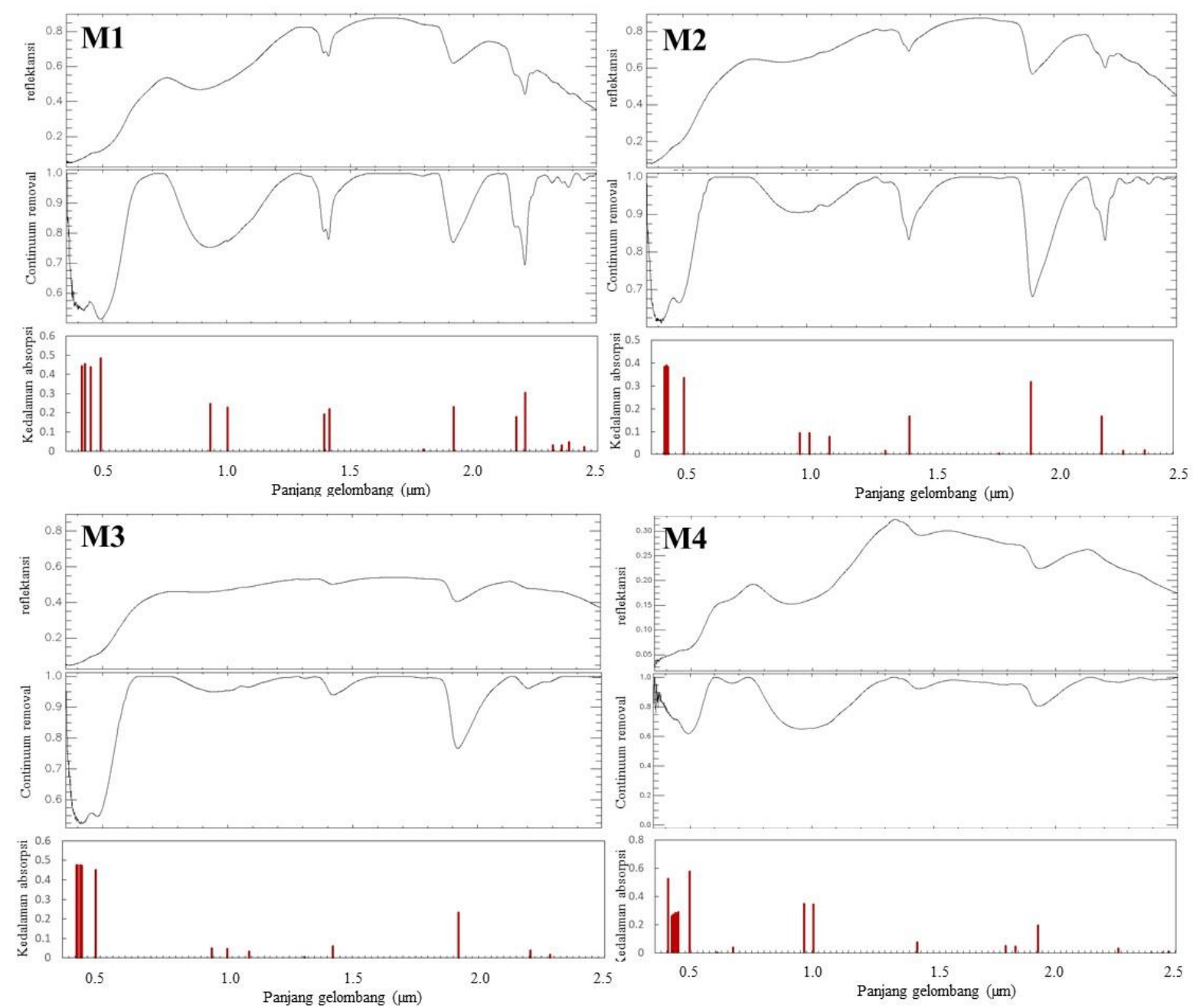

Gambar 5. Kurva reflektansi, normalisasi reflektansi dengan continuum removal, dan kedalaman absorpsi untuk masing-masing sampel M1 s.d. M4.

Sampel M4 memiliki aktifitas radiasi yang cukup tinggi bila dihitung dengan gamma scintillometer. Berdasarkan hasil pengamatan terdapat absorpsi cukup tipis pada $1.400-1.500 \mathrm{~nm}$ pada sampel tersebut yang menarik untuk dapat diperiksa lebih lanjut. Absorpsi ini identik dengan absorpsi uranium oksida yang memang berimpit dengan ciri khas absorpsi ikatan O-H dan N$\mathrm{H}$ [26]. Namun, hal ini perlu diverifikasi lebih lanjut untuk menentukan konsistensi pengaruh uranium oksida yang terdapat dalam sampel.
Hasil analisis dengan menggunakan metode linear spectral unmixing berbasis data spektral USGS menunjukkan bahwa molekul yang umum yang terdeteksi adalah $\mathrm{H}_{2} \mathrm{O}, \mathrm{OH}$, $\mathrm{CO}_{3}$, dan $\mathrm{NH}_{4}$. Golongan sulfat yang dipilih terlihat ketika ikatan $\mathrm{OH}$ hadir. Kelompok mineral yang memungkinkan untuk ditemui dengan contoh mineral tertentu berupa mineral lempung (illite, kaolinite, smectite, dickite) dan kelompok pyllosilicates lainnya.

\section{KESIMPULAN}

Komposisi spektral sampel yang mengandung mineral pembawa REE dan 
radioaktif dapat dijadikan basis data (database) spektroskopi reflektansi yang memperlihatkan karakteristik khas, khususnya pada absorpsi beberapa panjang gelombang tertentu. Kurva reflektansi hasil analisis sampel yang berasosiasi dengan endapan timah menunjukan adanya kenampakan absorpsi yang dapat menjadi karakteristik untuk kehadiran REE, khususnya pada rentang panjang gelombang VNIR. Identifikasi mineral pembawa REE ditemukan pada sampel tailing dan konsentrat. Karakteristik spektral reflektansi untuk sampel mineral radioaktif di Mamuju memberi informasi bahwa terdapat beberapa panjang gelombang kunci, terutama pada rentang SWIR. Hasil interpretasi mineral mayor antara lain: mineral lempung, sulfat, spesies $\mathrm{NH}_{4}$, dan mineral yang mengandung Al-OH lainnya. Meski demikian untuk beberapa sampel pada panjang gelombang VNIR diidentifikasi mengandung mineral besi oksida/hidroksida.

\section{UCAPAN TERIMA KASIH}

Kami mengucapkan terima kasih kepada PT Timah (Persero) Tbk dan Pusat Teknologi Bahan Galian Nuklir - Badan Tenaga Nuklir Nasional yang telah memberikan sampel untuk dianalisis. Penelitian ini didanai oleh Kementerian Riset, Teknologi, dan Pendidikan Tinggi melalui skema Penelitian Dasar Unggulan Perguruan Tinggi 2019.

\section{DAFTAR PUSTAKA}

[1] A. B. Pour, M. Hashim, and J. van Genderen, "Detection of hydrothermal alteration zones in a tropical region using satellite remote sensing data: Bau goldfield, Sarawak, Malaysia," Ore Geol. Rev., vol. 54, pp. 181-196, 2013.

[2] F. F. Sabins, "Remote sensing for mineral exploration," Ore Geol. Rev., vol. 14, pp. 157183, 1999.

[3] F. D. van der Meer, H. M. van der Werff, F. J. van Ruitenbeek, C. A. Hecker, W. H. Bakker, M.
F. Noomen, M. van der Meijde, E. J. M. Carranza, J. B. de Smeth, and T. Woldai, "Multiand hyperspectral geologic remote sensing: A review," Int. J. Appl. Earth Obs. Geoinf., vol. 14, no. 1, pp. 112-128, 2012.

[4] J. C. Mars and L. C. Rowan, "Spectral assessment of new ASTER SWIR surface reflectance data products for spectroscopic mapping of rocks and minerals," Remote Sens. Environ., vol. 114, no. 9 , pp. 2011-2025, 2010.

[5] I. Purwadi, H. van der Werff, and C. Lievens, "Reflectance spectroscopy and geochemical analysis of rare earth element-bearing tailings: A case study of two abandoned tin mine sites in Bangka Island, Indonesia," Int. J. Appl. Earth Obs. Geoinf., vol. 74, pp. 239-247, 2019.

[6] L. E. Vicente and C. R. de Souza Filho, "Identification of mineral components in tropical soils using reflectance spectroscopy and advanced spaceborne thermal emission and reflection radiometer (ASTER) data," Remote Sens. Environ., vol. 115, no. 8, pp. 1824-1836, 2011.

[7] P. Hauff, “An overview of VIS-NIR-SWIR field spectroscopy as applied to precious metals exploration," Arvada, Color. Spectr. Int. Inc, vol. 80001, pp. 303-403, 2008.

[8] G. R. Hunt, "Spectral signatures of particulate minerals in the visible and near infrared," Geophysics, vol. 42, no. 3, pp. 501-513, Apr. 1977.

[9] R. N. Clark, T. V. V King, M. Klejwa, G. A. Swayze, and N. Vergo, "High spectral resolution reflectance spectroscopy of minerals," $J$. Geophys. Res. Solid Earth, vol. 95, no. B8, pp. 12653-12680, Aug. 1990.

[10] P. E. Johnson, M. O. Smith, and J. B. Adams, "Simple algorithms for remote determination of mineral abundances and particle sizes from reflectance spectra," J. Geophys. Res. Planets, vol. 97, no. E2, pp. 2649-2657, Feb. 1992.

[11] S. Lolon and F. Rahman, "Overview of rare earth elements in Indonesia," Coal Asia, 2014.

[12] B. Soetopo, R. Witjahyati, and Y. Wusana, "Sintesa geologi dan pemineralan uranium Sektor Rabau Hulu, Kalan, Kalimantan Barat," in Seminar Geologi Nuklir dan Sumberdaya Tambang Tahun 2004, 2004, pp. 85-99.

[13] S. J. Suprapto, "Tinjauan tentang unsur tanah jarang," Bul. Sumber Daya Geol., vol. 4, no. 1, pp. 36-47, 2009.

[14] H. Syaeful, I. G. Sukadana, and A. Sumaryanto, "Radiometric Mapping for Naturally Occurring Radioactive Materials (NORM) assessment in Mamuju, West Sulawesi," Atom Indones., vol. 40, no. 1, p. 35,2014

[15] F. D. Indrastomo, I. G. Sukadana, and Suharji, "Identifikasi pola struktur geologi sebagai pengontrol sebaran mineral radioaktif berdasarkan kelurusan pada citra Landsat- 8 di 
Mamuju, Sulawesi Barat," Eksplorium, vol. 38, no. 2, pp. 71-80, 2017.

[16] F. D. Indrastomo, I. G. Sukadana, A. Saepuloh, A. H. Harsolumakso, and D. Kamajati, "Interpretasi vulkanostratigrafi daerah Mamuju berdasarkan analisis citra Landsat-8," Eksplorium, vol. 36, no. 2, pp. 71-88, 2015.

[17] M. I. J. Putra and Sobirin, "Mapping apatiteilmenite rare earth element mineralized zone using fuzzy logic method in Sijuk District, Belitung," Int. J. Remote Sens. Earth Sci., vol. 15, no. 1, pp. 1-14, 2018.

[18] Wikarno, D. A. D. Suyatna, and S. Sukardi, "Granitoids of Sumatra and the Tin Islands BT Geology of Tin Deposits in Asia and the Pacific," 1988, pp. 571-589.

[19] J. A. Katili, "Structure and age of the indonesian tin belt with special reference to Bangka," Tectonophysics, vol. 4, no. 4, pp. 403-418, 1967.

[20] F. S. Mu'awanah, B. Priadi, Widodo, I. G. Sukadana, and R. Ardiansyah, "Uranium mobility on active stream sediment in Mamuju area, West Sulawesi," Eksplorium, vol. 39, no. 2, pp. 95104, 2018.

[21] A. N. H. Hede, Syafrizal, and S. Gunawan, "Assessment of granitoid-related mineralization using visible near-infrared and shortwave infrared reflectance spectroscopy," in International Symposium on Earth Science and Technology 2018, 2018, pp. 144-149.

[22] I. G. Sukadana, F. D. Indrastomo, and Ngadenin, "Distribution of rock alteration based on $\mathrm{Th} / \mathrm{U}$ ratio in Tapalang, Mamuju, West Sulawesi," Ris. Geo. Tam, vol. 28 no. 2, pp. 141-155, 2018.

[23] I. G. Sukadana, A. Harijoko, and L. D. Setijadji, "Tectonic setting of Adang Volcanic Complex in Mamuju Region, West Sulawesi Province," Eksplorium, vol. 36, no. 1, pp. 31-44, 2015.

[24] Syafrizal, A. N. H. Hede, and A. O. Nabilla, "Using grain mineralogy to observe the rare earth element content of alluvial tin on Bangka Island, Indonesia," in International Symposium on Earth Science and Technology 2018, 2018, pp. 605608.

[25] D. J. Turner, "Reflectance spectroscopy and imaging spectroscopy of rare earth elementbearing mineral and rock samples," The University of Columbia, 2015.

[26] J. W. Plaue, G. L. Klunder, I. D. Hutcheon, and K. R. Czerwinski, "Near infrared reflectance spectroscopy as a process signature in uranium oxides," J. Radioanal. Nucl. Chem., vol. 296, no. 1, pp. 551-555, 2013. 